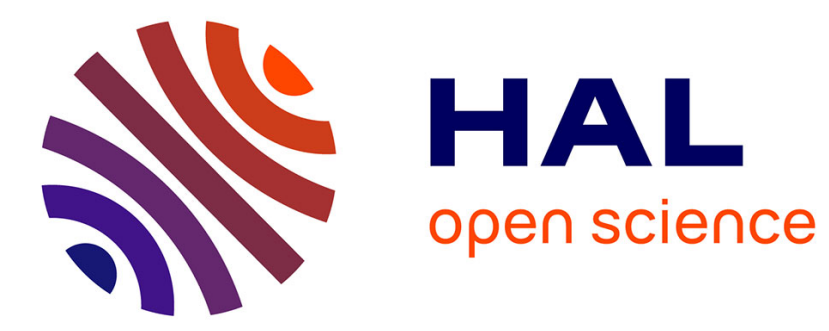

\title{
New Augmented Reality Taxonomy: Technologies and Features of Augmented Environment.
}

\author{
Olivier Hugues, Philippe Fuchs, Olivier Nannipieri
}

\section{To cite this version:}

Olivier Hugues, Philippe Fuchs, Olivier Nannipieri. New Augmented Reality Taxonomy: Technologies and Features of Augmented Environment.. Furht, Borko. Handbook of Augmented Reality, Springer, pp.850, 2011, 978-1-4614-0063-9. hal-00595204

\section{HAL Id: hal-00595204 \\ https://hal.science/hal-00595204}

Submitted on 24 May 2011

HAL is a multi-disciplinary open access archive for the deposit and dissemination of scientific research documents, whether they are published or not. The documents may come from teaching and research institutions in France or abroad, or from public or private research centers.
L'archive ouverte pluridisciplinaire HAL, est destinée au dépôt et à la diffusion de documents scientifiques de niveau recherche, publiés ou non, émanant des établissements d'enseignement et de recherche français ou étrangers, des laboratoires publics ou privés. 


\title{
Chapter 1 New Augmented Reality Taxonomy : Technologies and Features of Augmented Environment
}

\author{
Olivier Hugues ${ }^{\star}$, Philippe Fuchs ${ }^{\star \star}$ and Olivier Nannipieri ${ }^{\star \star \star}$
}

\begin{abstract}
This article has a dual aim: firstly to define augmented reality (AR) environments and secondly, based on our definition, a new taxonomy enabling these environments to be classified. After briefly reviewing existing classifications, we define AR by its purpose, ie. to enable someone to create sensorymotor and cognitive activities in a new space combining the real environment and a virtual environment. Below we present our functional taxonomy of AR environments. We divide these environments into two distinct groups. The first concerns the different functionalities enabling us to discover and understand our environment, an augmented perception of reality. The second corresponds to applications whose aim is to create an artificial environment. Finally, more than a functional difference, we demonstrate that it is possible to consider that both types of AR have a pragmatic purpose. The difference therefore seems to lie in the ability of both types of AR to free themselves or not of location in time and space.
\end{abstract}

\subsection{Introduction}

It is indisputable that augmented reality (AR) is the result of a series of technological innovations. However, does reducing AR to a set of technical characteristics in behavioural interfacing not lead us to underestimate the wealth of AR and its functionalities? We are therefore entitled to naively ask

^ ESTIA Recherche, MaxSea, LaBRI, France. o.hugues@net.estia.fr

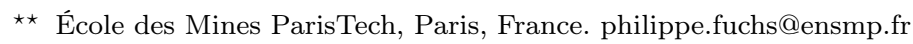

$\star \star \star$ Université du Sud, Toulon, and Université de la Méditerranée, Marseille, France. fk.olivier@mac.com 
the following question: what is augmented in augmented reality? If reality is by definition everything that exists, then strictly speaking reality cannot be augmented since it is already everything. So what is augmented? Initially the answer seems obvious: it is not reality, but the perception of reality which is augmented. From this perspective, the question of what is real, existence and properties is not examined here. The issue concerns perception, ie. the phenomenon - reality as it is perceived, not the noumen - reality in itself, to use Kant's words [1].

\subsection{Augmented perception?}

We can find in literature two main movements which define perception. On the one hand (a passive conception), the sensory system passively receives stimulations and processes this information so as to refer to internal representations. On the other (an active conception), it is the extraction of regularity between actions and stimulations which enable perception. It seems that the current movement is rather to consider perception using the sensorymotor approach (the second case), in opposition to the linear and sequential approach of the perception process, the first case [2]. Furthermore, this is confirmed by Gibson [3] who considers the senses as full perceptory systems ("perception is to extract, thanks to movements, this information by detecting its invariants"). It is important to emphasise that like Auvray and Fuchs [2] who used the theoretical framework proposed by Bergson in "Matrer and Memory" [4], that any perception and any knowledge have only one final aim - whether conscious or not: action. We do not perceive and do not attempt to familiarise ourselves in order to know but rather to act. Inherited from the pragmatic conception of William James [5], the Bergsonian theory insists on the nature itself of our perception and any search for information in the real world: perception is never disinterested, knowledge is only ever a means to acting better in the real world [4] - and surviving for wild animals or being happier for humans. Although any increase in the quantity of information - and consequently, any increase in our understanding of reality - admitted by AR aims for greater mastery of what is real, it is clear that, from a technological point of view, AR can offer interfaces which propose either, more explicitly, information, or, more explicitly, a better mastery of our actions with regard to real events. But how do technical devices modify our perception? According to [2], "using a new technical device modifies our sensory-motor relationship with the environment; and subsequently it modifies our perception". Technical tools modify our "perceptory space". The step is decisive. However, we cannot "only" endeavour to perceive better since perception is not a final aim in itself, but rather a means of achieving a target action [4]. In the manner of virtual reality (VR), augmenting reality may satisfy two objectives for the user: encourage understanding and mastery of 
the real world and therefore, an augmented perception of reality on the one hand and, on the other hand, propose a new environment whose aim does not appear to be obey either requirements in terms of knowledge or practical requirements.

\subsection{Final aim and birth of a taxonomy}

Globally, the aim of AR is to enable a person to carry out sensory-motor and cognitive activities in a new space by associating the real environment and a virtual environment. Yet, like VR [6], AR can propose either a modellisation of the real world based on an environment which imitates or symbolises the real world, or the creation of an artificial environment which does not correspond to anything which exists. It is on the basis of this distinction that it is possible to propose a functional taxonomy of AR and draw a certain number of relative implications, namely, with regard to variations in space and time references allowed by AR.

\subsection{Taxonomy of Interactives Mixed Systems}

There have been many attempts to classify augmented reality environments since this technology is in fact a sub-set of environments or mixed systems.

Whether technical, functional or conceptual, these taxonomies often aim to describe, compare and generate [7]. We present an overview of some of the taxonomies present in literature. Readers will find a more complete review of classifications in [8].

\subsubsection{Conceptual taxonomies}

In [9], the authors proposed a framework for analysis with which they explore different mixed environments so as to identify the common use of human abilities linked with the physical world, the body and the social environment. However, since the advantage of mixed environments is their ability not to faithfully reproduce reality [10], the authors proposed six factors like the power of expression, efficiency, ergonomics and accessibility enabling the use of the physical world to be weighted. This classification enables a large number of possibilities for interaction generated by mixed systems to be highlighted. In [11], Mackay proposes a classification of mixed interfaces whose common denominator is the target of augmentations. Different targets are users, objects of interaction and the environment. Dubois [12] extends this 
classification by introducing a methodology rating known as ASUR, extended in 2003 [13] and whose discretisation includes the user, the adaptor ${ }^{4}$, the system and real entities. Later, Renevier [14] defined methods of interaction as passive (determined by the system) or active (determined by the user). Creating, accessing, modifying and destroying links depends on the methods of interaction. A link is defined as being short-lived or persistent and can be located with regard to users. Different types of locating are possible. The authors also define three types of interaction: the users interact with objects via links and inversely, and links are used for communication between users.

\subsubsection{Technical taxonomies}

In $[15,16]$, the authors propose a technological classification now well known under the name of "virtuality-reality continuum". They endeavour to discretise and classify the environment according to four categories. This continuum highlights the fact that there is a progressive transition from real to virtual and inversely. The authors of [17] chose to analyse the user's movements in order to extract its framework based on expected movements, captured movements and desired movements. By using Norman's theory of action [18], the authors proposes dissociating the systems which augment performance from systems which augment evaluation.

\subsubsection{Functional taxonomies}

With the aim of clarifying concepts which underlie the combination of the real world and virtual world, Dubois et al.[19] propose a classification broken down into two distinct parts: the first characteristic is the purpose of the task and the second is the type of augmentation. Whilst the purpose of the task enables the authors to augment and specify the Milgram continuum [15] by adding to it two continua so as to distinguish augmented reality from virtual reality, the second characteristic enables the existence of two different functional types of augmentations to be underlined. The first consists of an "augmented performance" whilst the second is an "augmented perception". According to the authors, the first type of augmentation enables users to carry out tasks in the real world in a new way like for example with the "Active Badge" [20] whilst the second, much more common concerning AR systems, enables relevant information to be provided for the task in hand.

4 Adaptors transfer data from one world to the other and may be the system's input or output. 


\subsection{Proposal for a functional taxonomy for AR}

We propose distinguishing several AR functionalities whose organisation is presented in Figure 1.1.

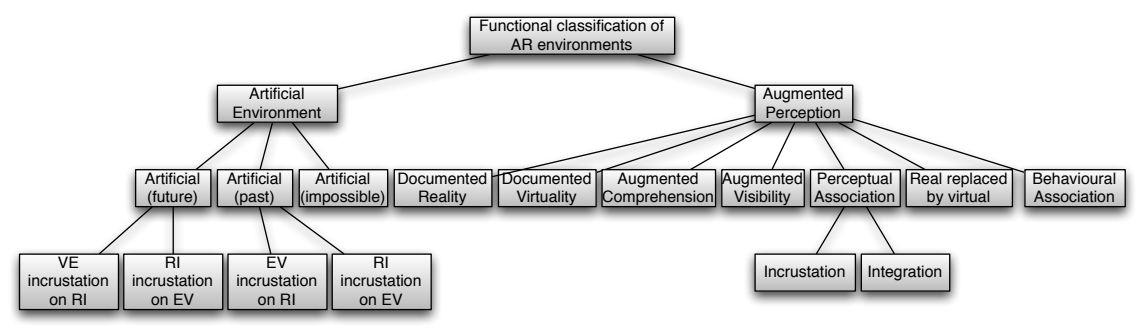

Fig. 1.1: Functional classification of AR. (RI : image with "real" content, $\mathrm{VE}$ : virtual entity)

\subsubsection{Functionality 1: augmented perception of reality}

This first functionality consists of highlighting the fact that AR constitutes a tool for assisting decision-making. It can provide information which will enable a better understanding of reality and which will ultimately optimise our action on reality.

Fuchs [21] proposes a taxonomy which considers the means by which AR enables this objective to be achieved. Five types of environments can be distinguished. To these five type of environment, we can add another type to which Fuchs [21] attributes the functionality 0 . This is the case where real images (RI) and virtual entities (VE) are displayed on the same screen, but without any relationship between the two. In this case, the user has a single screen with two independent displays. We then talk about functionality 0 because there is no relation between the content of VE and RI. With the exception of this case of a limited AR environment, which is possible but not relevant, other environments are possible and more relevant. Specifically, the augmented perception of reality functionality can be divided into five sub-functionalities. 


\subsubsection{Sub-functionality 1: Documented reality and documented virtuality}

This is the minimum functionality of augmented reality: RI and VE are in two different display boxes, but their information is related. Augmentation thus consists of informing users, like for example, without the mediation of a technical device, an assembly manual for kit furniture. The aim of the second display box (mostly text) is to help users understand and guide their action. This is documented reality.

Inversely, in some specific cases, for example, the synoptic of an industrial process (VE) with the "real time" incorporation of one or several windows displaying real parts of the process (RI), the "document" no longer consists of a virtual environment, but of images of the real object. In this particular case, we can talk about documented virtuality. In both these cases it involves improving the understanding of the real or virtual scene by adding passive semantic information provided on another display support.

\subsubsection{Sub-functionality 2: Reality with augmented perception or understanding}

In this functionality, RI ad VE are in the same display box. Two levels can be distinguished according to the contribution of augmentation.

\section{First level: Reality with augmented understanding.}

This involves augmenting the understanding of images from the real scene by incrusting passive semantic information (Figure 1.2). VE (titles, keys, symbols, etc.), more or less visually close to real objects, providing complementary information on the latter (eg. functions, references). Inversing RI and VE in this functionality cannot be envisaged. 


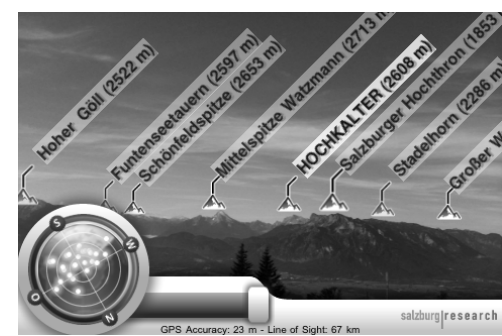

(a) Peak.AR [22].

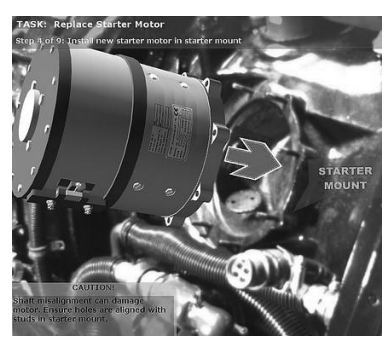

(b) ARMAR [23, 24].

Fig. 1.2: Example of applying the augmented understanding of reality.

\section{Second level: Reality with augmented visibility.}

This is the augmented visibility of images from real scenes (if we limit ourselves to visual perception). VE (eg. "iron wire" model of real objects) geometrically match the contours of real objects (Figure 1.3). They enable objects to be highlighted so as to see them better. This involves, amongst other things, calibrating cameras. It is then possible either to improve the clarity of images by highlighting the apparent contours of objects so as to perceive them more easily or to improve the understanding of objects by virtually representing their visible and invisible contours.

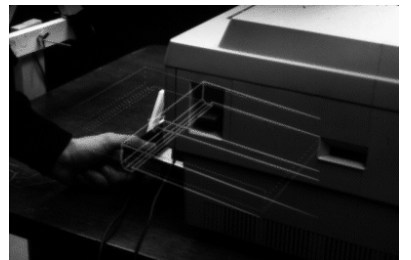

(a) Karma [25].

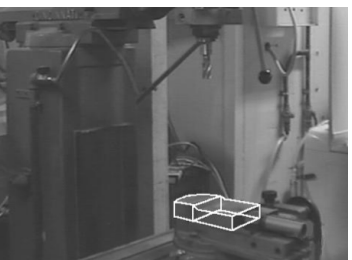

(b) Visualisation of a mechanical part [21].

Fig. 1.3: Reality with augmented visibility with objects' visible and invisible contours represented. 


\subsubsection{Sub-functionality 3: Perceptual association of the real and virtual}

In this functionality new virtual objects are added to the real scene. We can distinguish between both cases according to the level of integration of virtual objects in the real scene.

First level: Incrustation of virtual objects on real images.

Virtual objects are incrusted (overlay) on top of real objects. Therefore virtual objects are not concealed by real objects. We can refer to this as association by superposition (Figure 1.4a).

Second level: Integration of virtual objects on real images.

Virtual objects are integrated with real objects. The latter conceal virtual objects which are positioned behind them. This is a 3D association. However integration with real time occlusion remains a major technological hurdle (Figure 1.4b).

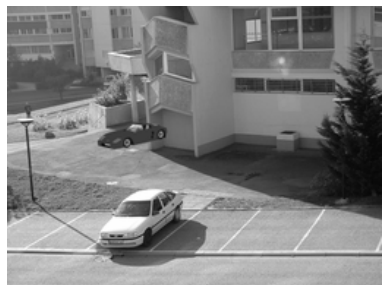

(a) Incrustation of objects.

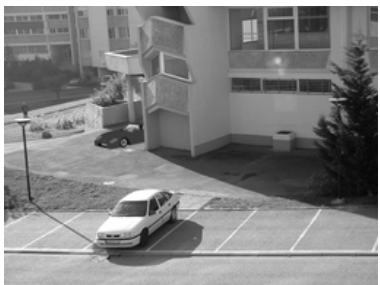

(b) Integration of objects.

Fig. 1.4: Examples of perceptual associations between the real and virtual (extract from [26]).

\subsubsection{Sub-functionality 4: Behavioural association of the real and virtual}

In addition to the conditions of the previous functionality, we semantically modellise virtual objects by taking into account their physical properties according to the laws of gravity, contact, elasticity, fluidity, etc. so as to 
enrich the scene. Prior knowledge is used in the real scene and its objects. This functionality defines geometrical and physical interactions between real and virtual objects. For example, we can mention the behaviour and attraction functions of virtual objects with real objects.

\subsubsection{Sub-functionality 5: substituting the real by the virtual or virtualised reality}

If we know the geometrical modellisation of the real scene observed, we can replace the video image display for the real scene by the synthetic image of the model, determined from the same point of view. By going from the video image to the synthetic image, and vice versa, the understanding for the environment is augmented. In this case we can talk about virtualised reality. We can then also change the point of view for the synthetic image, without moving the camera filming the real scene, which enables a better understanding of the scene. For example, we can mention teleoperation work carried out at the DER by EDF (Figure 1.5). In their visualisation device, the video image display for the real scene is not replaced by the model's synthetic image, but they are displayed on two neighbouring screens. The robot, which the operator is handling, is simultaneously displayed in real $3 \mathrm{D}$ images and synthetic 3D images. Whatever the point of view of real cameras, the operator can always observe on a screen in virtualised reality the mechanical configuration of the robot with "real time" animated synthetic images.

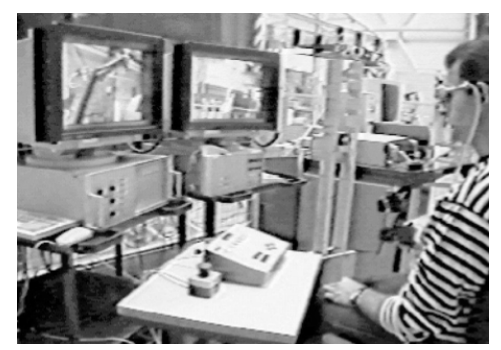

Fig. 1.5: The teleoperated robot is displayed simultaneously in real 3D images and using 3D artificial images. 


\subsubsection{Functionality 2: create an artificial environment}

In the first functionality, AR enables objects, beings or relations which exist in reality but which cannot be perceived by users to be visualised, eg. underground stations [27] exist in reality, but are not always easily identifiable. An iPhone ${ }^{\circledR}$ application shows (or highlights) what exists in reality but cannot be seen. It is clear that with regard to the Bergsonian theory of perception, all our activities, even the most speculative (eg. thinking, modellising) concern actions [4]. However, humans have an ability which seems to partly escape this law: imagination. We can reasonably acknowledge that the production of mental images may not satisfy a practical objective, although what we imagine may or not have voluntary effects on our perception and actions in the real world. The production of unconscious mental images (ie. dreams) and conscious mental images (ie. fantasies, defined as the production of mental images during the awakening phase, eg. when we imagine that we are in other places) does not seem to serve any practical function. When we form mental images of an imaginary environment it is not in order to act in the real world, but perhaps, on the contrary, an attempt to escape reality. However, AR is able to produce such environments which are no longer subject to practical requirements. In such cases, AR offers environments which present not reality as they are perceived - by augmenting the amount of information which we are unable to perceive, but which, however, is present in reality - but reality, as it could be in the future or even an impossible reality.

\subsubsection{Sub-functionality 1: imagine reality as it could be in the future by associating the real and the virtual}

Overall this is not about being informed, understanding or even acting with regard to what really exists, but digitally creating a possible world which combines either a real environment with virtual images (level 1) or a virtual environment with real images (level 2). Each level can be broken down into two sub-levels according to the type of association. This type of functionality can use two types associations: with occlusion versus without occlusion.

\section{First level: imagine a possible future environment by incrusting virtual objects on/in real images.}

First sub-level: no occlusion.

In this functionality, new virtual objects are added to the real scene by superposition and are not concealed, not to better understand and/or act in reality, but with a disinterested aim, for example, strictly aesthetic. 
Second sub-level: with occlusion.

This involves adding virtual objects which conceal part of the real environment. Obviously, this is more efficient at the sub-level than the real/virtual association because it enables users to visualise what the possible future environment looks like if these virtual objects incrusted in the real environment really existed. Thus, an interface enabling one of the rooms of a real apartment to be visualised (eg. the user's) by adding virtual furniture [28]would not enable them to know or master reality any better, but to imagine what the future reality would be like.

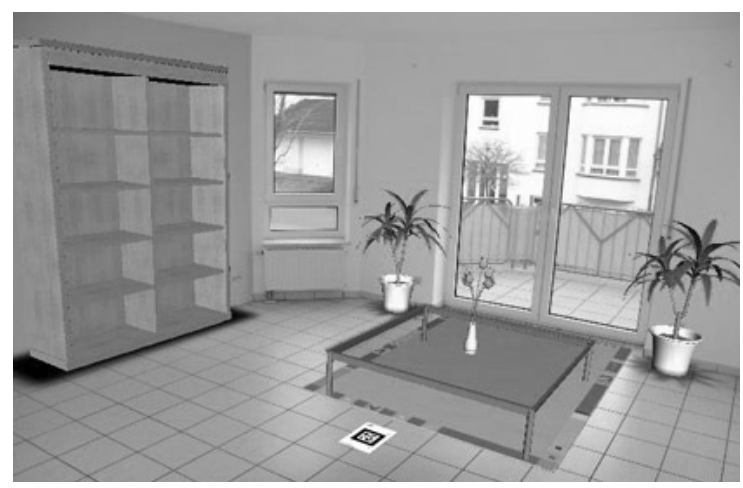

Fig. 1.6: Example of a possible future environment by incrusting virtual elements [28].

Second level: imagine a possible future environment by incrustrating real objects in/on a virtual environment.

First sub-level: without occlusion.

In this functionality, we added by superposition, without occlusion, new real objects to the virtual environment. Here again, for example, to satisfy an aesthetic objective, it would involve seeing in what type of room (virtual), the real object would be best suited, by revealing all its aesthetic qualities. We could, for example, virtually move the real image of a sculpture in virtual rooms of a future exhibition venue so as to estimate the optimal location (according to constraints such as light, access for visitors, etc.). 
Second sub-level: with occlusion.

Here again, the this second sub-level takes on its full meaning with the integration of real images in a virtual environment: the designer of the future exhibition venue may visualise what visitors really see if they visited this venue with such a configuration.

\subsubsection{Sub-functionality 2: Imagine reality as it was by associating the real and virtual.}

Likewise, it is possible, either to associate virtual objects which no longer exist with a real environment (level 1) or associate objects which still exist but which were present in an environment which no longer exists and which is, consequently, digitally created (level 2). And in each of these cases, this association can be done without (sub-level 1) or with occlusion (sub-level 2).

\section{First level: imagine a past environment by incrusting virtual objects on/in real images.}

First sub-level: with occlusion.

With this objective in mind, the objective is to visualise what current scenes looked like in the past without incrusting virtual objects belonging to the past and concealing the current environment.

Second sub-level: with occlusion.

Partial occlusion of the real present environment by virtual objects enables the past to be imagined as faithfully as possible. AR therefore plays the role of a "virtual memory". For example, the mixed environment which proposes adding, with occlusion, to the current Cluny Abbey building architectural items which have since disappeared enables the abbey to exist as it did then [29]. We can thus see Cluny Abbey as it was when it was built in the 10th century (Figure 1.7). 


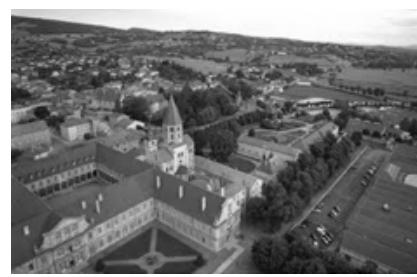

(a) Present environment.

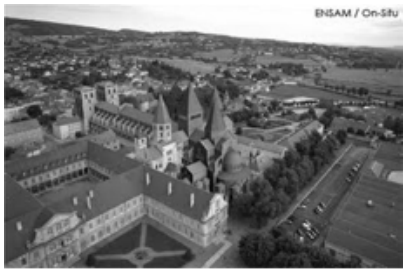

(b) Both past and present environment.

Fig. 1.7: Present Cluny Abbey augmented with items belonging to its past [29].

Second level: imagine a past environment by incrusting real objects in/on a virtual environment.

First sub-level: without occlusion.

This functionality is clearly very limited: it is certainly possible to put in its past context the real image, for example, of a column in the city of Ephesus in tact in a virtual environment by digitally creating the city of Ephesus (today in ruins) without occlusion. Yet, the advantage of such as association is almost non-existent.

Second sub-level: with occlusion.

On the other hand, incrusting with occlusion the real image of the column of Ephesus in a virtual environment representing the city of Ephesus before it was subject to the ravages of time enables us to much more easily imagine the place and function of this column at the time when it was built on the site of Ephesus.

\subsubsection{Sub-functionality 3: imagine an impossible reality}

This functionality makes better use of the potential of AR with regard to its possible distance from reality by taking advantage of the imaginary dimension of mixed environments. Here the objective is not to inform, or encourage understanding or optimise users' actions. This functionality emphasises the potentially disinterested nature of mixed environments: it is possible to create an environment which cannot really exist, eg. artistic creations or systems 
whose final aim is purely aesthetic. Designers therefore have greater relative freedom and are not limited to the types of environments which they can use: they can go beyond the possibilities that this environment really offers and the means used may be very varied. Concretely, it is possible to use all types of environments in the augmented reality perception functionality. Without systematically and exhaustively listing all the types of artificial mixed environments, it is possible to give a few examples. The principle for all possible sub-functionalities consists of diverting the primary function of AR, ie. augmented perception of reality. Creating an artificial AR environment can for example be envisaged thanks to a semantic gap produced by the incoherence of the overall meaning of the mixed environment. Diverting sub-functionality $\mathrm{n}^{\circ} 1$ (documented reality and documented virtuality) of the first functionality (augmented perception of reality) involves associating, for example, with a real environment a virtual "document" providing information out of step with this environment with the aim of provoking in users a modification of the meaning of reality as it is perceived by users due to the difference between the real image and virtual information. We could for example associate with a real environment a virtual "document" erroneously describing this environment. Synthesising these mutually incompatible meanings would provoke in users the representation of an impossible mixed artificial environment. We could create an environment where a real image is augmented with erroneous meanings (ie. "documents"), ie. incoherent with the real image, but this would be a minimum functionality. The potential of AR is best exploited in environments which for example propose diverting the primary function of integrating virtual objects in a real scene (second level of sub-functionality 3 : perceptual association of the real and the virtual). This is the case of the AR game developed by Dassault Systems for Nestlé [30] (Figure 1.8a), where a virtual character moves, partially concealing the real image, on a cereal box. Although this environment obeys objectives defined by a marketing strategy (eg. increasing traffic to Chocapic ${ }^{\circledR}$ 's website and creating a strong emotional link between the brand and its target, in this case young children), these objectives are merely an indirect consequence of the experience of young users. Basically, this environment creates an impossible artificial universe where a Minimoys ${ }^{\circledR}$ character runs across a cereal box. The aim is neither about better understanding reality nor more effectively mastering it. Although the final objective is interested (ie. making young consumers loyal), the system in itself could well have not obeyed any practical objective. It suffices to see how adults (who are not the target of this PR operation) adapt this game. In other words, what this type of environment attempts to create is a feeling of presence in an artificial world. And what at the end of the day this world contributes to strengthening the links between players and the brand of cereals is not fundamental, even though the game was created with this objective in mind. It is possible to distance oneself even further from the practical constraints when for example proposing an impossible mixed artificial environment such as the view of a US city "through the windows" of an apartment 
located in France [31] (Figure 1.8b). An application which enables users to enjoy the view of a suspension bridge in the US from the window of their Parisian apartment has no practical, only an aesthetic use. With Wiimote ${ }^{\circledR}$ placed on the window ledge between two windows and an infrared sensor on the user's head, when moving around the room, the corner view of windows changes so as to give the illusion that the apartment is located in the US.

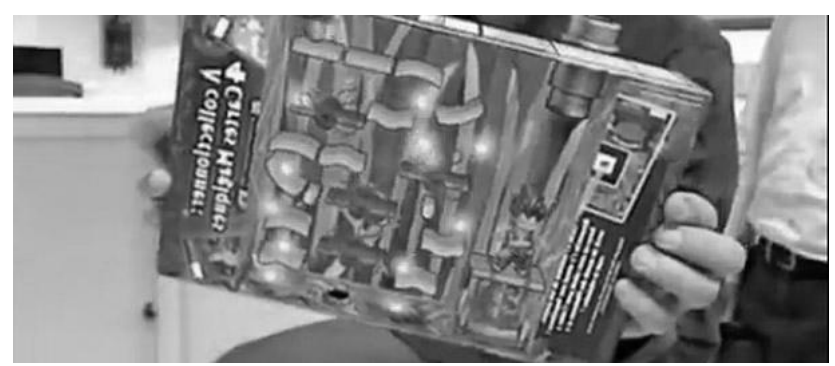

(a) Chocapic and Nestlé [30].

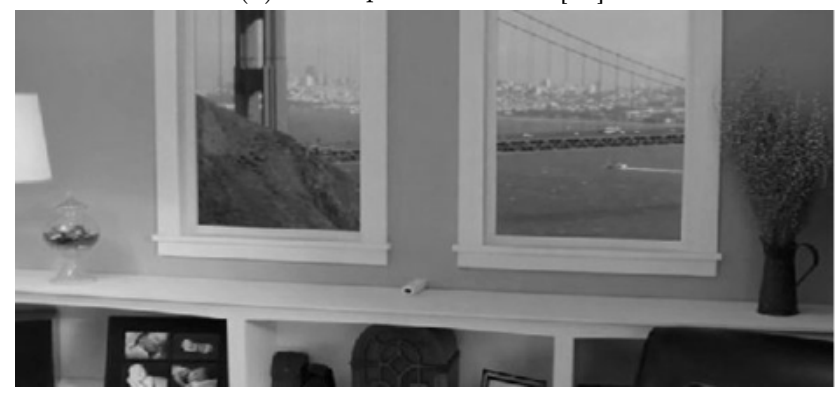

(b) "Virtual windows" [31].

Fig. 1.8: Examples of artificial AR environments.

\subsection{Discussion}

The distinction between AR environments whose function is to augment the perception of reality and those whose function is to immerse users in an artificial environment has a double implication. The first concerns the fact that the taxonomy cannot be designed as a classification with a merely descriptive vocation. Taxonomy has a generative dimension [7]. Concretely, more than just a simple classification tool of what already exists, it enables environments which it is possible to design to emerge. In this respect, taxonomy is a tool for assisting the creation of virtual and augmented reality environments. 
This reflection leads to the second major implication of analysing what has been done here. The difference between the two types of AR goes further than a simple distinction in terms of functionality: if the first type of AR (ie. functionality 1: augmented perception of reality) is a prisoner of the present, the second type (ie. functionality 2: imagine) goes far beyond it. In short, AR enables us, admittedly, to see, understand and master the present better, and it also enables us to propose an environment with which the designer and, consequently, users can play with location in time. When I see, thanks to an AR interface today the ruins of Cluny Abbey augmented with parts of this abbey which have disappeared [29], I see an environment which is neither pure present nor pure past, but a mixture of both the past and present. Likewise, when I see my currently empty living-room augmented with its future furniture [28], I am neither in the present nor the future, but in a reality where both present and future are mixed. And when "hrough" the windows of my Parisian apartment I see a US city [31], I perceive a world which is simply not possible. This is why AR enables us, not only, to free ourselves from reality's time categories (ie. past vs present vs future), but also from the spatial unity which characterises reality, which, for example, means I cannot see a US city by looking through the window of my apartment. When, for example, I am looking for the closest underground station thanks to an application available on my mobile [27], this enables me to go there here and now: the first functionality of AR (ie. AR with an informative and practical aim) does not modify the space perceived, it only aims to unveil parts of that space - in this case underground stations - which are not perceived, but which may rightly be perceived since they do exist. On the other hand, whether it is Cluny Abbey [29] or a furnished room [28], the items added modify the structure of current real spatial relations. In short, from the spatial point of view, the first type of AR does not modify anything, it only reveals what already exists: it updates the spatial structure of reality, whether this structure can be directly perceived by the senses (eg. Paris underground stations), whether it is the expression of causal relations scientifically shown based on calculations (eg. an environment which shows the existing electrical voltage between two items on an electric meter) or whether it can only be apprehended via an artificial technique (eg. an AR environment which would make something visible thanks to a thermal camera for light waves whose frequency escapes human sight). On the contrary, the second type of AR modifies the spatial structure by adding objects, beings or relations which do not belong to it: it modifies the spatial configuration of reality.

\subsection{Conclusion}

To summarise, strictly speaking, there are two major differences between the two types of AR: it is functional in so far as both AR do not satisfy the same 
objectives - one is practical, the other imaginary. However, this distinction is not fundamental because it can be argued that, just like the interface enables me to locate underground stations on my mobile [27], the aim of Cluny Abbey in mixed reality [29] is to at least provide knowledge (ie. knowing what this abbey looked like when it was built) and even my virtually furnished has a practical function (ie. enabling me to buy furniture or not according to the layout of the room). The basic distinction between the two AR therefore seems to correspond to the ability of both to be go beyond location in space and time or not. Whilst the first type of AR presents us reality (what I can see, what I can do), the second type, on the contrary, presents us what is imaginary: what I cannot really see - since it is not actually real - but which I can, paradoxically, see thanks to an AR interface. In short, the second type of AR enables us to go from what is put into action (ie. current) to what is not: the imaginary. And this imaginary may be possible or not. Finally, AR makes the impossible possible. 



\section{Index}

Augmented Perception, 1-6, 14, 16 Augmented Reality, 1-5, 10, 12-17

Functionality, 5, 6, 8-14, 16

Real Images, 5, 6

Reality, 1-3, 5, 10, 11, 13, 14, 16, 17
Taxonomy, 1, 3-5, 15

Virtual Entities, 5, 6

Virtual Reality, 2-4

Virtuality, 4, 6, 14

Virtuality-reality continuum, 4 


\section{References}

1. E. Kant, Kritik der reinen vernunft, J.F Hartknoch. Critique de la raison pure. éd. Riga (trad. fr. Delamarre, A. et Marty F.). Gallimard, Paris, 1980, 1781-1787.

2. M. Auvray and P. Fuchs, "Perception, immersion et interaction sensorimotrices en environnement virtuel," In A. Grumbach \& E. Klinger (Eds.), Réalité Virtuelle et Cognition. Numéro spécial de Intellectica, vol. 45, no. 1, pp. 23-35, 2007.

3. J. Gibson, The senses considered as perceptual systems. Boston: Houghton Mifflin, 1966.

4. H. Bergson, Matière et mémoire. Essai sur la relation du corps à l'esprit. Première édition : 1939. Paris : Les Presses universitaires de France, 1965, 72e édition. Collection : Bibliothèque de philosophie contemporaine, 1939.

5. W. James, Pragmatism: A new name for some old ways of thinking. New York : Longman Green and Co, 1907.

6. P. Fuchs and G. Moreau, "Le Traité de la Réalité Virtuelle," Presse de l'Ecole des Mines de Paris, Troisième Edition. Mars 2006.

7. M. Beaudouin-Lafon, "Instrumental interaction: an interaction model for designing post-wimp user interfaces," in CHI '00: Proceedings of the SIGCHI conference on Human factors in computing systems, (New York, NY, USA), pp. 446-453, ACM, 2000 .

8. L. Nigay and J. Coutaz, "Espaces conceptuels pour l'interaction multimédia et multimodale," TSI spécial multimédia et collecticiel, AFCET et Hermes Publ., vol. 15, no. 9, pp. 1195-1225, 1996.

9. R. J. Jacob, A. Girouard, L. M. Hirshfield, and M. S. Horn, "Reality-Based Interaction: A Framework for Post-WIMP Interfaces," pp. 201-210, ACM Press, Florence, Italy, April 5-10 2008.

10. P. Dourish, Where the Action is : The Foundations of Embodied Interaction. MIT Press, Décembre 2001.

11. W. E. Mackay, "Augmenting reality: A new paradigm for interacting with computers," World Proceedings of ECSCW'93, the European Conference on Computer Supported Cooperative Work, vol. 7, 1996.

12. E. Dubois, Laurence Nigay, J. Troccaz, O. Chavanon, and L. Carrat, "Classification space for augmented surgery, an augmented reality case study," In A. Sasse and C. Johnson (eds.), Proceedings of Interact'99, IOS Press. Edinburgh (UK), pp. 353-359, 1999.

13. E. Dubois, P. Gray, and L. Nigay, "ASUR ++ : supporting the design of mobile mixed systems," Interacting with Computer, pp. 497-520, 2003.

14. P. Renevier, Système Mixtes Collaboratifs sur Supports Mobiles : Conception et Réalisation. Spécialité informatique, Université Joseph Fournier - Grenoble 1, Grenoble, Juin 2004 .

15. P. Milgram and F. Kishino, "A taxonomy of mixed reality visual displays," in IEICE Transactions on Informations Systems [16], pp. 1-15.

16. P. Milgram, H. Takemura, A. Utsumi, and F. Kishino, "Augmented reality: A class of displays on the reality-virtuality continuum," Telemanipulator and Telepresence Technologie, vol. 2351, pp. 282-292, 1994.

17. S. Benford, H. Schnädelbach, B. Koleva, R. Anastasi, C. Greenhalgh, T. Rodden, J. Green, A. Ghali, T. Pridmore, B. Gaver, A. Boucher, B. Walker, S. Pennington, A. Schmidt, H. Gellersen, and A. Steed, "Expected, sensed, and desired: A framework for designing sensing-based interaction," ACM Trans. Comput.-Hum. Interact., vol. 12, no. 1, pp. 3-30, 2005.

18. D. A. Norman, "Cognitive engineering," Book chapter of User Centered System Design, New Perspectives on Human-Computer Interaction, pp. 31-61, 1986. 
19. E. Dubois, L. Nigay, and J. Troccaz, "Combinons le monde virtuel et le monde réel : Classification et principe de conception," Actes des Rencontres Jeunes Chercheurs en Interaction Homme-Machine, pp. 31-34, Mai 2000.

20. R. Want, A. Hopper, V. Falc ao, and J. Gibbons, "The active badge location system," ACM Trans. Inf. Syst., vol. 10, no. 1, pp. 91-102, 1992.

21. P. Fuchs, G. Moreau, and J. Papin, "Le Traité de la Réalité Virtuelle," Presse de l'Ecole des Mines de Paris. Première Edition, Mars 2001.

22. S. Research, "Peak.ar : http://peakar.salzburgresearch.at/."

23. S. Henderson and S. Feiner, "Augmented reality for maintenance and repair (armar)," Technical Report AFRL-RH-WP-TR-2007-0112, United States Air Force Research Lab, Jul 2007.

24. S. J. Henderson and S. Feiner, "Evaluating the benefits of augmented reality for task localization in maintenance of an armored personnel carrier turret," Mixed and Augmented Reality, IEEE / ACM International Symposium on, pp. 135-144, 2009.

25. S. Feiner, B. Macintyre, and D. Seligmann, "Knowledge-based augmented reality," Commun. ACM, vol. 36, no. 7, pp. 53-62, 1993.

26. S. Gibson, A. Chalmers, G. Simon, J.-F. Vigueras Gomez, M.-O. Berger, D. Stricker, and W. Kresse, "Photorealistic Augmented Reality," in Second IEEE and ACM International Symposium on Mixed and Augmented Reality - ISMAR'03, (Tokyo, Japon), p. 3 p, IEEE, ACM, none, 102003.

27. Presselite, "Metro paris : http://www.presselite.com/iphone/metroparis/."

28. Meine Wohnung, "Click \& Design : http://www.meinewohnung.cc/."

29. ENSAM - On-Situ, "Dispositif de réalité augmentée pour l'abbaye de cluny : Ray-on. http://www.on-situ.com/."

30. D. Nestle, "Minimoys : http://minimoys.3ds.com/press/3DVIA-Nestle.html."

31. Rationalcraft, "Winscape : http://www.rationalcraft.com/Winscape.html." 